\title{
KD16-U1, A NEW METABOLITE OF STREPTOMYCES: ISOLATION AND STRUCTURAL STUDIES
}

\author{
Kuniaki Tatsuta, Tsutomu Tsuchiya, Nobuyoshi Mikami \\ and Sumio Umezawa \\ Department of Applied Chemistry, Faculty of Engineering, Keio University, \\ Hiyoshi, Yokohama, Japan \\ Hamao Umezawa and Hiroshi Naganawa \\ Institute of Microbial Chemistry, \\ Kamiosaki, Shinagawa-ku, Tokyo, Japan \\ (Received for publication April 25, 1974)
}

\begin{abstract}
A new metabolite, KD16-U1, has been isolated from the culture of Streptomyces filipinensis. The structure of the metabolite elucidated in this paper has been found to be closely related to shikimic acid.
\end{abstract}

Since the chemical screening of microbial metabolites was first described in the isolation of dienomycins ${ }^{1)}$ which had antibacterial and local anesthetic activities, a number of new metabolites such as antipain ${ }^{2)}$, $\operatorname{arglecin}{ }^{3)}$, and phosphoramidon ${ }^{4}$ have been found by the screening in our laboratories. In the present paper, we wish to report the isolation and structural elucidation of metabolite KD16-U1 (1). This new metabolite is produced by Streptomyces filipinensis ${ }^{5)}$ (the Laboratory No. KD16-C2), and is positive to triphenyltetrazolium chloride (TTC). The screening method used was substantially similar to that described in a previous paper ${ }^{1}$.

\section{Production and Isolation}

Fermentations were conducted for 4 days at $27^{\circ} \mathrm{C}$ in a medium (pH 7.0) containing starch $2.0 \%$, glucose $2.0 \%$, soy-bean meal $2.0 \%$, yeast extract $0.5 \%$ and sodium chloride $0.25 \%$. The compound KD16-U1 in the culture filtrate (5 liters) was adsorbed on charcoal (100 g), eluted with $50 \%$ aqueous acetone at $\mathrm{pH} 8.0$, and purified by successive column chromatography with cellulose ("Avicel", $400 \mathrm{~g}, 4.5 \times 65 \mathrm{~cm} ; n$-butanol-ethanol-water, $4: 1: 2$ ) and silica gel (Mallinckrodt, $150 \mathrm{~g}, 3.0 \times 70 \mathrm{~cm}$; ethyl acetate-methanol, $4: 1$ ). Recrystallization of the crude product $(450 \mathrm{mg})$ from ethanol-ethyl acetate gave colorless needles $(290 \mathrm{mg}), \mathrm{mp} 113 \sim 114^{\circ} \mathrm{C}$; $[\alpha]_{D}^{20}-168^{\circ}\left(c \quad 1.0, \mathrm{H}_{2} \mathrm{O}\right)$.

\section{Chemical and Physical Properties}

KD16-U1 is a neutral substance positive to TTC (red), Tollens (brown), Ehrlich (light red) and diacetyl (yellow), but negative to ninhydrin reagents. It can also be detected under ultraviolet light of wavelength $254 \mathrm{~nm}$ as a dark spot.

KD16-U1 is soluble in water, methanol, ethanol, dimethylformamide and dimethylsulfoxide, but almost insoluble in ethyl acetate, benzene, chloroform and ether. KD16-U1 is stable in 
Fig. 1.

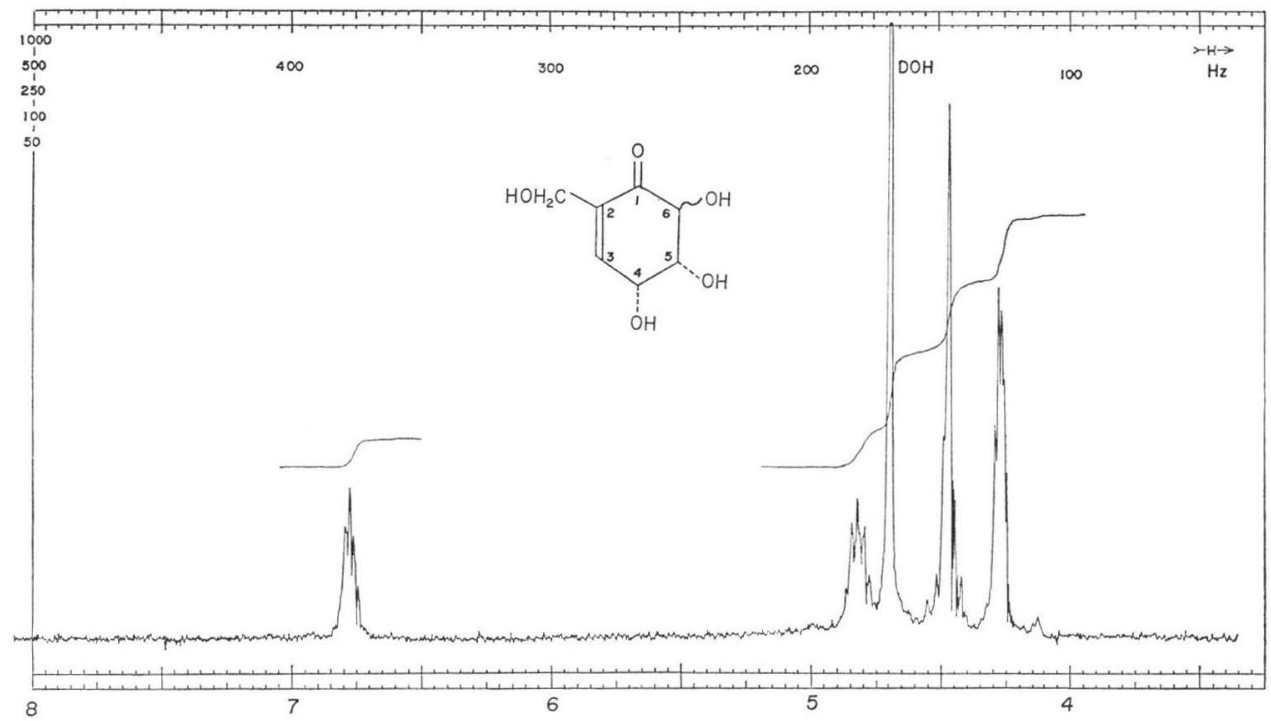

aqueous acidic and neutral conditions, but extremely unstable toward alkali, darkening immediately. KD16-U1 shows single spots at $\mathrm{Rf} 0.30$ and 0.32 on thin-layer chromatogram (TLC) of cellulose "Avicel" with solvent systems: $n$-butanol-ethanol-water $(4: 1: 2)$ and $n$ butanol-acetic acid-water $(12: 3: 5)$, respectively and also shows a single spot at $\mathrm{Rf} 0.47$ on TLC of silica gel with ethyl acetate - methanol (4:1).

KD16-U1 analyzed for $\mathrm{C}_{7} \mathrm{H}_{10} \mathrm{O}_{5}$. Found: $\mathrm{C} 48.55, \mathrm{H} 5.93, \mathrm{O} 45.5 \%$, Calcd: C 48.27 , $\mathrm{H} 5.79, \mathrm{O} 45.94 \%$. The mass spectrum showed the following prominent peaks: $\mathrm{m} / \mathrm{e} 174$ $\left(\mathrm{C}_{7} \mathrm{H}_{10} \mathrm{O}_{5}^{+}\right), 156,143,138,127,126,125,114,112,111,110,109,96$. The ultraviolet spectrum of KD16-U1 shows the following maxima $(\varepsilon)$ : $229(9,500)$ and $311 \mathrm{~nm}(60)$ in water and in $0.1 \mathrm{~N}$ hydrochloric acid; $218(3,900), 265(7,600)$ and $300 \mathrm{~nm}$ (sh., 2,900) in $0.1 \mathrm{~N}$ sodium hydroxide. The infrared spectrum of KD16-U1 showed absorptions at $3450 \sim 3250(\mathrm{OH}), 2880$ $(\mathrm{CH}), 1690(\mathrm{C}=\mathrm{O}), 1650 \sim 1625 \mathrm{~cm}^{-1}(\mathrm{C}=\mathrm{C})$. The NMR spectrum (100 MHz) of $\mathrm{KD} 16-\mathrm{U} 1$ in deuterium oxide (Fig. 1) showed 2-proton multiplet at $\delta$ 4.27, 2-proton multiplet at $\delta 4.46,1$ proton multiplet at $\delta 4.82$ (a methine proton) and 1-proton multiplet at $\delta 6.78$ (an olefinic proton). The $\mathrm{CD}$ spectrum ( $c 0.081$ in water) of KD16-U1 gave the following molecular ellipticities: $[\theta]_{222} 0,[\theta]_{240}-4.04 \times 10^{4},[\theta]_{280} 0,[\theta]_{303}+6.08 \times 10^{2}$ and $[\theta]_{33 n}+1.27 \times 10^{2}$.

\section{Structure of KD16-U1}

The mass spectrum, elemental analysis and NMR spectrum of KD16-U1 (1) indicate the presence of three unsaturation number and four active hydrogens exchangeable with deuterium. The UV and IR absorption bands are of the $\alpha, \beta$-unsaturated ketone type. These results suggest that KD16-U1 is a cyclic tetrol having $\alpha, \beta$-unsaturated ketone.

Acetylation of 1 with acetic anhydride and sulfuric acid or perchloric acid gave a syrupy tetraacetyl derivative $\mathbf{3}$. The UV spectrum of $\mathbf{3}$ was similar to that of $\mathbf{1}$, suggesting that the 
Fig. 2.

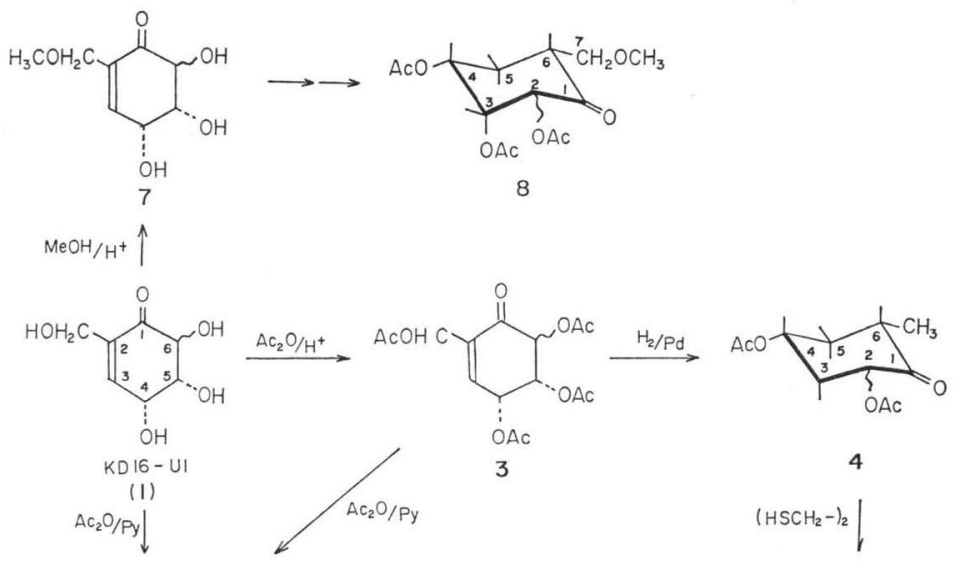<smiles>CC(=O)OCc1cc(OC(C)=O)cc(OC(C)=O)c1OC(C)=O</smiles>

2

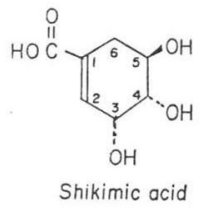

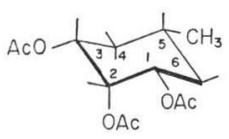

6

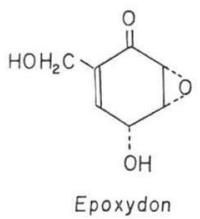

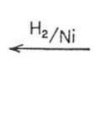

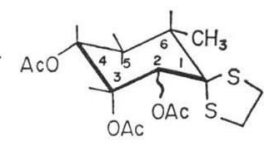

5<smiles>CC1=C(O)C(O)C2OC2C1=O</smiles>

chromophore is not changed by acetylation. Acetylation of $\mathbf{1}$ with pyridine and acetic anhydride gave an aromatized O-acetyl derivative 2 as crystalline plates. The product was shown to be identical with 2,3,5-tri-O-acetylbenzyl acetate, which was derived from epoxidon ${ }^{6)}$, a fungal metabolite, with $\beta$-elimination in the similar condition. Treatment of $\mathbf{3}$ with pyridine and acetic anhydride also gave 2. It is known $^{7)}$ that, on treatment with base, certain six-membered polyol having an $\alpha, \beta$-unsaturated ketone are aromatized with $\beta$-elimination. The above observations support the structure of 1 to be six-membered trihydroxy-2-enone having a hydroxymethyl side chain.

Hydrogenation of 3 with palladium black proceeded smoothly to give a ketone 4 (IR: $\left.1710 \mathrm{~cm}^{-1}\right)$. The NMR spectrum of 4 showed the presence of a methyl $\left(\delta 1.14, \mathrm{CH}_{3}-6\right)$ and a methylene group $\left(\delta 1.9 \sim 2.2, \mathrm{H}-5\right.$ and $\left.5^{\prime}\right)$ with the disappearance of an acetyl group in 3 . Hydrogenation of KD16-U1 in a similar way gave a ketone having a methyl group, however, the compound could not be purified because of its instability. Since it is known ${ }^{8)}$ that catalytic hydrogenation readily converts an allylic hydroxymethyl group into a methyl group, the above results show that the hydroxymethyl side chain of 1 is attached to a double bond. The presence of the signals assignable to one olefinic proton $(\delta 6.78)$ in $\mathbf{1}$ and the disappearance of the signals in 4 also supported this conclusion.

Using double resonance NMR studies on 4 (see experimental), the methyl group was confirmed to be adjacent to the ketone group and the sequence of $-\mathrm{CO}-\mathrm{CH}\left(\mathrm{CH}_{3}\right)-\mathrm{CH}_{2}-$ was also found. At the same time, the following coupling constants were clarified: $J_{2,3} 3.1 \mathrm{~Hz}, J_{3,4} 2.5 \mathrm{~Hz}$, 
$J_{4,5 \mathrm{e}} 5.0 \mathrm{~Hz}, J_{4,5 \mathrm{a}} 11.5 \mathrm{~Hz}, J_{5 \mathrm{e}, 8} 5.5 \mathrm{~Hz}$ and $J_{5 \mathrm{a}, 6} 13.0 \mathrm{~Hz}$, thus indicating that the equatorially oriented protons were $\mathrm{H}-3$ and $\mathrm{H}-5 \mathrm{e}$ and $\mathrm{H}-4, \mathrm{H}-5 \mathrm{a}$ and $\mathrm{H}-6$ were axial. The results support the chair conformation of 4 . Long-range coupling $\left(J_{3,5 \mathrm{e}} \sim 2 \mathrm{~Hz}\right.$; W-conformation) also support the above conclusion. The long-range coupling $\left(J_{2,0} \sim 1 \mathrm{~Hz}\right)$ did not exclude ${ }^{9)}$ the sequence of $-\mathrm{CH}_{(2)}-\mathrm{CO}-\mathrm{CH}_{(6)}\left(\mathrm{CH}_{3}\right)^{-}$. However, the configuration of $\mathrm{H}-2$ is not yet decided.

To remove the ketone group, 4 was converted to the thioketal 5 with ethanedithiol and it was desulfurized with RANEY nickel to give an optically inactive syrup of 6 . The NMR spectrum of 6 showed the presence of a plane of symmetry in its chair conformation, to which one equatorial methine proton $(\mathrm{H}-2)$ and three axial ones $(\mathrm{H}-1, \mathrm{H}-3, \mathrm{H}-5)$ were attached, thus, suggesting the equatorial orientation of $2-\mathrm{O}-\mathrm{Ac}$ grouping in 4 . However, the configuration at C- 6 of 1 does not reflect that of $\mathrm{C}-1$ in $\mathbf{6}$, because a keto-enol tautomerism would be expected to occur between $\mathrm{C}-1$ and $\mathrm{C}-6$ during the reactions.

When 1 was treated with methanol and sulfuric acid similarly to the preparation of $\mathbf{3}$, a monomethylated derivative (7) was obtained. Hydrogenation of 7 with palladium balck followed by acetylation with acetic anhydride and perchloric acid gave the mono-O-methyl-tri-Oacetylated derivative 8 . In the NMR spectrum of $\mathbf{8}$, the chemical shifts of all signals except for those of the grouping $-\mathrm{CH}_{(\theta)}-\mathrm{CH}_{2} \mathrm{OCH}_{3}$ were found to be identical with those of 4 , indicating that only the primary alcohol was methylated.

From the above observations, the structure of KD16-U1 was decided to be $4 \alpha, 5 \alpha, 6$ ?trihydroxy-2-hydroxymethyl-cyclohex-2-enone (1) or its enantiomer.

The above structure is closely related to that of shikimic acid, which has the same molecular formula $\left(\mathrm{C}_{7} \mathrm{H}_{10} \mathrm{O}_{5}\right)$ and has $\mathrm{CH}_{2}$ and $\mathrm{CO}_{2} \mathrm{H}$ instead of $\mathrm{C}=\mathrm{O}$ and $\mathrm{CH}_{2} \mathrm{OH}$ of KD16-U1. As mentioned above, the configurations of $\mathrm{C}-4$ and $\mathrm{C}-5$ of $\mathrm{KD} 16-\mathrm{U} 1$ are the same as those of $\mathrm{C}-3$ and $\mathrm{C}-4$ of shikimic acid ${ }^{10)}$. Consequently, the optical rotation of KD16-U1 (1) contiguous to that of shikimic acid $\left[[\alpha]_{\mathrm{D}}-183^{\circ}\right.$ (water)] suggests that the configuration of $\mathrm{C}-6$ of 1 may be the same as that of $\mathrm{C}-5$ of shikimic acid.

It is noteworthy that a metabolite of Streptomyces, KD16-U1 is structurally related to a constituent of plants shikimic acid and fungal metabolites epoxidon and terremutin ${ }^{11}$.

\section{Experimental}

Thin-layer chromatograms (TLC) were performed using silica gel ("Silica-Rider" purchased from Daiichi Pure Chemicals Co.) or microcrystalline cellulose powder ("Avicel" purchased from Funakoshi Yakuhin Co.) and the chromatograms were visualized by spraying with triphenyltetrazolium chloride or sulfuric acid, or under ultraviolet light of wave-length $254 \mathrm{~nm}$. The NMR spectra were recorded with Varian-A-60D and HA-100D spectrometers. Tetramethylsilane (for the solution of deuterochloroform or benzene- $d_{6}$ ) and sodium 4, 4'-dimethyl-4-silapentane-1sulfonate (for the solution of deuterium oxide) were used as the internal standards. The CD spectra were recorded with a Japan Spectroscopic Co. spectropolarimeter (JASCO Model ORDUV-5).

Treatment of KD16-U1 with acetic anhydride and pyridine (formation of 2 from 1 ).

To an ice-cold solution of KD16-U1 $(208 \mathrm{mg})$ in pyridine $(6 \mathrm{ml})$, acetic anhydride $(3 \mathrm{ml})$ was added and the solution was allowed to stand overnight at room temperature. On TLC with silica gel [developed with benzene-ethyl acetate (4:1)] and with "Avicel" [developed with $n$-butanol-ethanol-water $(4: 1: 2)$ ], a spot ( $\operatorname{Rf} 0.54$ and $\operatorname{Rf} 0.51$, respectively) appeared. After 
addition of a small volume of ethanol, the solution was evaporated. Repeated recrystallization of the residue from isopropyl alcohol gave colorless plates of 2 ; yield $298 \mathrm{mg}(77 \%)$; mp $93 \sim$ $94^{\circ} \mathrm{C},[\alpha]_{\mathrm{D}}^{20} 0^{\circ}$ (c 2.0, methanol) (lit. ${ }^{6)}: \mathrm{mp} 87 \sim 89^{\circ} / 92 \sim 94^{\circ} \mathrm{C}$ ).

Found: C 55.80, H 5.23, O 39.30. Calcd. for $\mathrm{C}_{15} \mathrm{H}_{18} \mathrm{O}_{8}$ : C 55.55, H 4.97, C $39.47 \%$.

Mass spectrum (m/e): 324 (molecular ion), 282, 240, 198, 197, 155, 154, 149, 138.

The IR, UV and NMR spectra were identical with those of 2,3,5-tri-O-acetylbenzyl acetate derived from epoxidon ${ }^{6)}$.

Acidic acetylation of KD16-U1 (formation of 3).

(a) With sulfuric acid. To a suspension of KD16-U1 $(200 \mathrm{mg})$ in acetic anhydride $(2.0 \mathrm{ml})$, a few drops of conc. sulfuric acid were added; the resulting solution was heated at $100^{\circ} \mathrm{C}$ for 30 minutes and poured into an ice-cold water $(30 \mathrm{ml})$. The mixture was extracted with ethyl acetate $(10 \mathrm{ml} \times 3)$. The extracts were washed with water $(10 \mathrm{ml} \times 3)$, dried over sodium sulfate and evaporated. The residue $(358 \mathrm{mg}$ ), which showed single spots ( $\mathrm{Rf} 0.46$ and $\mathrm{Rf} 0.49$, respectively) on TLC with silica gel developed with benzene-ethyl acetate (4:1) and chloroform - ethyl acetate $(4: 1)$ respectively, was chromatographed on a column $(25 \times 300 \mathrm{~mm})$ of silica gel ( $40 \mathrm{~g}$ ) with chloroform - ethyl acetate (4:1), and the fraction of $65 \sim 106 \mathrm{ml}$ was evaporated to give a thick syrup of 3 ; yield $255 \mathrm{mg}(64 \%) ;[\alpha]_{\mathrm{D}}^{24}-86^{\circ}$ (c 1.0, chloroform).

Found: C 52.62, H 5.22. Calcd. for $\mathrm{C}_{15} \mathrm{H}_{18} \mathrm{O}_{9}$ : C 52.63, H $5.30 \%$.

Mass spectrum $(m / e)$ : 342 (molecular ion), 300, 283, 282, 240, 198, 180, 169, 156.

IR spectrum: $\sim 2920(\mathrm{CH}), 1755(\mathrm{OAc}), 1710(\mathrm{C}=\mathrm{O}), \sim 1655(\mathrm{C}=\mathrm{C}), 1375(\mathrm{OAc}), 1220$ $\mathrm{cm}^{-1}$.

UV spectrum: $\lambda_{\max }^{\mathrm{EtOH}} 227 \mathrm{~nm}(\varepsilon 8,400)$.

NMR spectrum (benzene $-d_{6}, 100 \mathrm{MHz}$ ): $\delta 1.55,1.58,1.68$ and 1.77 (each $\left.3 \mathrm{H}, \mathrm{s}, \mathrm{OAc}\right), 4.74$ $\left(2 \mathrm{H}, \mathrm{m}, \mathrm{CH}_{2}-2\right), 5.49(1 \mathrm{H}, \mathrm{d}, \mathrm{H}-6), 5.66(1 \mathrm{H}, \mathrm{m}, \mathrm{H}-4), 5.94(1 \mathrm{H}$, double $\mathrm{q}, \mathrm{H}-5), 6.28(1 \mathrm{H}$, $\mathrm{m}, \mathrm{H}-3)$. On irradiation at $\delta 4.74\left(\mathrm{CH}_{2}-2\right)$, multiplets at $\delta 6.28(\mathrm{H}-3)$ and $5.66(\mathrm{H}-4)$ collapsed

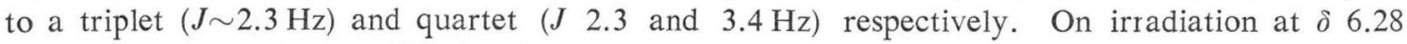
(H-3), the signals due to $\mathrm{CH}_{2}-2$ collapsed to an eight-line signals with the inner four being most intense (typical for the $\mathrm{AB}$ part of an $\mathrm{ABX}$ system), the signals due to $\mathrm{H}-4$ collapsed to a double triplet $(J 2.2$ and $3.4 \mathrm{~Hz}$ ) and the signals due to $\mathrm{H}-5$ collapsed to a quartet $(J 3.4$ and $2.6 \mathrm{~Hz})$. On irradiation at $\delta 5.94(\mathrm{H}-5)$, a doublet at $\delta 5.49(\mathrm{H}-6)$ collapsed to a singlet. The following coupling constants were concluded: $J_{\mathrm{CH}_{2}, 3} 1.5 \mathrm{~Hz}, J_{\mathrm{CH}_{2}, 4} 2.2 \mathrm{~Hz}$ (a homoallylic coupling, $J_{3,4} 2.3 \mathrm{~Hz}, J_{3,5} \sim 2.3 \mathrm{~Hz}$ (a long-range coupling in the W-conformation), $J_{4,5} 3.4 \mathrm{~Hz}$, $J_{5,6} 2.6 \mathrm{~Hz}$.

CD spectrum (c 0.084 in dioxane): $[\theta]_{210}-1.89 \times 10^{4},[\theta]_{227}-5.99 \times 10^{4},[\theta]_{265} 0,[\theta]_{321}+13.5$ $\times 10^{2},[\theta]_{360}+3.2 \times 10^{2}$.

(b) With perchloric acid. To a suspension of KD16-U1 (75 mg) in ethyl acetate $(3 \mathrm{ml})$, acetic anhydride $(1 \mathrm{ml})$ containing a drop of $70 \%$ perchloric acid was added. The resulting solution was kept at room temperature for 2 hours and poured into ice water. The mixture was extracted with chloroform. The extract was successively washed with $5 \%$ aqueous sodium bicarbonate and water, dried over sodium sulfate and concentrated to a syrup, which was purified by the same method as described above to give a syrup, yield $141 \mathrm{mg}$ (96\%), which was identical with 3 .

Hydrogenation of 3 (formation of 4 ).

A solution of $3(430 \mathrm{mg})$ in ethanol $(16 \mathrm{ml})$ was hydrogenated with palladium black and hydrogen under 50 p.s.i. at room temperature for 10 minutes. The solution was filtered and the filtrate was evaporated to give a residue $(350 \mathrm{mg})$, which gave a single spot $(\mathrm{Rf} 0.40)$ on TLC with silica gel and benzene-ethyl acetate $(6: 1)$. The residue was chromatographed on a short column of silica gel with benzene-ethyl acetate $(6: 1)$ to give a thick syrup of 4 ; yield $285 \mathrm{mg}(80 \%) ;[\alpha]_{\mathrm{D}}^{25}+60^{\circ}$ (c 1.0, chloroform).

Found: C 54.30, H 6.39. Calcd. for $\mathrm{C}_{13} \mathrm{H}_{18} \mathrm{O}_{7}$ : C 54.53, H 6.35\%.

Mass spectrum $(m / e)$ : 286 (molecular ion), 258, 244, 226, 223, 205, 202, 201, 184, 166, 
$159,149,142,124$.

IR spectrum: $2950(\mathrm{CH}), 1750(\mathrm{OAc}), 1710(\mathrm{C}=\mathrm{O}), 1375(\mathrm{OAc}), 1250,1225 \mathrm{~cm}^{-1}$.

NMR spectrum $\left(\mathrm{CDCl}_{3}, 100 \mathrm{MHz}\right): \delta 1.14,\left(3 \mathrm{H}, \mathrm{d}, \mathrm{CH}_{3}-6\right), 1.92(1 \mathrm{H}, \mathrm{m}, \mathrm{H}-5 \mathrm{a}), 2.15$ $(1 \mathrm{H}, \mathrm{m}, \mathrm{H}-5 \mathrm{e}), 2.02,2.09$ and 2.13 (each $3 \mathrm{H}, \mathrm{s}, \mathrm{OAc})$; $2.61(1 \mathrm{H}, \mathrm{m}, \mathrm{H}-6), 5.38(1 \mathrm{H}, \mathrm{q}, \mathrm{H}-2)$, $5.38\left(1 \mathrm{H}, \mathrm{dq}, \mathrm{H}^{-4}\right), 5.80(1 \mathrm{H}, \mathrm{m}, \mathrm{H}-3)$. On irradiation at $\delta 1.14\left(\mathrm{CH}_{3}-6\right)$, a multiplet at $\delta$ $2.61(\mathrm{H}-6)$ changed into a slightly unresolved quartet $(J 5.5$ and $13.0 \mathrm{~Hz})$ with a small coupling $(J \sim 1.0 \mathrm{~Hz})$. On simultaneous irradiation at $\delta 1.92(\mathrm{H}-5 \mathrm{a})$ and $2.15(\mathrm{H}-5 \mathrm{e})$, a double quartet $(\mathrm{H}-4)$ at $\delta 5.38$ collapsed to a doublet $(J 2.5 \mathrm{~Hz})$ overlapped with an unchanged quartet $(\mathrm{H}-2)$, and a multiplet at $\delta 5.80(\mathrm{H}-3)$ collapsed to a quartet $(J 3.1$ and $2.5 \mathrm{~Hz})$. On irradiation at $\delta$ $5.38(\mathrm{H}-2$ and $\mathrm{H}-4)$, a multiplet at $\delta 5.80(\mathrm{H}-3)$ collapsed to a doublet $(J \sim 2 \mathrm{~Hz})$ with changes of signals due to $\mathrm{H}-5 \mathrm{a}, \mathrm{H}-5 \mathrm{e}$ and $\mathrm{H}-6$. On irradiation at $\delta 5.80(\mathrm{H}-3)$, a quartet $(\mathrm{H}-2)$ and a double quartet $(\mathrm{H}-4)$ at $\delta 5.38$ collapsed to a doublet $(J \sim 1.0 \mathrm{~Hz})$ and a quartet $(J 5.0$ and $11.5 \mathrm{~Hz}$ ) respectively, with a change of $\mathrm{H}-5 \mathrm{e}$ signal. The following coupling constants were concluded: $J_{2,3} 3.1 \mathrm{~Hz}, J_{2,8} \sim 1.0 \mathrm{~Hz}$ (a long-range coupling), $J_{3,4} 2.5 \mathrm{~Hz}, J_{3,5 \mathrm{e}} \sim 2 \mathrm{~Hz}$ (a longrange coupling in the W-conformation), $J_{4,5 \mathrm{a}} 11.5 \mathrm{~Hz}, J_{4,5 \mathrm{e}} 5.0 \mathrm{~Hz}, J_{5 \mathrm{a}, 6} 13.0 \mathrm{~Hz}, J_{5 \mathrm{e}, 8} 5.5 \mathrm{~Hz}$. $\times 10^{2}$.

CD spectrum (c 0.086 in methanol): $[\theta]_{205}-7.0 \times 10^{4},[\theta]_{250} 0,[\theta]_{317}+16.8 \times 10^{2},[\theta]_{380}+2.99$

Treatment of $\mathbf{4}$ with ethanedithiol (formation of $\mathbf{5}$ ).

A solution of $4(140 \mathrm{mg} ; 0.49 \mathrm{mmol})$ in ethanedithiol $(92 \mathrm{mg} ; 0.98 \mathrm{mmol})$ was treated with boron trifluoride etherate $(0.22 \mathrm{ml})$ at room temperature for 1 hour. To the resulting solution, ice-cold chloroform $(6 \mathrm{ml})$ was added and the mixture was washed with ice-cold $2 \%$ sodium bicarbonate solution and water, and dried over sodium sulfate. After removal of the solvent, the residue, was chromatographed on a short column of silica gel with benzene-ethyl acetate $(6: 1)$ to give colorless plates of $\mathbf{5}$, which was recrystallized from ethanol; yield $149 \mathrm{mg}(83 \%)$; $\mathrm{mp} 131 \sim 132^{\circ} \mathrm{C},[\alpha]_{\mathrm{D}}^{27}+23^{\circ}$ (c 1.0 , chloroform).

Found: C 49.63, H 6.28, S 17.54. Calcd. for $\mathrm{C}_{15} \mathrm{H}_{22} \mathrm{O}_{8} \mathrm{~S}_{2}: \mathrm{C} 49.70, \mathrm{H} 6.13, \mathrm{~S} 17.69 \%$.

Mass spectrum $(\mathrm{m} / \mathrm{e}): 362$ (molecular ion), 320, 319, 302, 278, 270, 266, 260, 259, 242, 214, 201, 200, 199, 182, 172, 149, 145, 140, 132.

IR spectrum (KBr disk): $\sim 2930(\mathrm{CH}), 1735$ (OAc), $\sim 1370(\mathrm{OAc}), 1250,1230 \mathrm{~cm}^{-1}$.

NMR spectrum $\left(\mathrm{CDCl}_{3}, 60 \mathrm{MHz}\right): \delta 1.30\left(3 \mathrm{H}, \mathrm{d}, J \sim 6 \mathrm{~Hz}, \mathrm{CH}_{3}-6\right), 1.7 \sim 2.3(2 \mathrm{H}, \mathrm{m}$, $\mathrm{H}-5 \mathrm{a}$ and $\mathrm{H}-5 \mathrm{e}), 2.00,2.08$ and 2.16 (each $3 \mathrm{H}, \mathrm{s}, \mathrm{OAc}) ; \sim 3.2\left[4 \mathrm{H}, \mathrm{m},\left(-\mathrm{S}-\mathrm{CH}_{2}\right)_{2}\right], 4.97(1 \mathrm{H}$, m, H-4), $5.18(1 \mathrm{H}, \mathrm{d}, J \sim 3 \mathrm{~Hz}, \mathrm{H}-2), 5.51[1 \mathrm{H}$, a triplet $(J \sim 3 \mathrm{~Hz})$ with a small coupling $(J<1 \mathrm{~Hz}), \mathrm{H}-3]$.

Desulfurization of 5 (formation of 6 ).

A mixture of $5(150 \mathrm{mg})$ and RANEY nickel $(\mathrm{T}-4 ; 0.2 \mathrm{ml})$ in ethanol $(7 \mathrm{ml})$ was stirred under reflux for 30 minutes with hydrogen introduced. The solution was filtered and the filtrate was repeatedly (three times) treated with fresh RANEY nickel in the same way. On TLC with silica gel and isopropyl ether- $n$-hexane $(3: 1)$, the starting material 5 ( $R f 0.40$ ) disappeared and two spots of $\mathrm{Rf} 0.70$ (minor) and 0.46 (major) appeared. The crude product $(40.5 \mathrm{mg}$ ) was chromatographed on a column $(10 \times 150 \mathrm{~mm})$ of silica gel $(4 \mathrm{~g})$ with isopropyl ether $-n$-hexane $(3: 1)$. The fraction $(7 \sim 9 \mathrm{ml})$ containing the minor product ( $\mathrm{Rf} 0.70$ ) was evaporated to give a syrup $(6 \mathrm{mg})$. The NMR spectrum showed the presence of two acetoxy groups $(\delta 2.00$ and 2.10). This minor product was not further investigated. The fraction $(15 \sim 23 \mathrm{ml})$ containing the major product ( $\mathrm{Rf} 0.46)$ was evaporated to give a thick syrup of 6; yield $24 \mathrm{mg}(21 \%)$; $[\alpha]_{\mathrm{D}}^{25} 0^{\circ}(c 1.0$, chloroform).

Found: C 57.56, H 7.24. Calcd. for $\mathrm{C}_{13} \mathrm{H}_{20} \mathrm{O}_{6}$ : C 57.34, $\mathrm{H} 7.40 \%$.

Mass spectrum $(m / e): 272$ (molecular ion), 230, 212, 188, 170, 152, 149, 128, 127, 126, 110.

IR spectrum: 2920, $2850(\mathrm{CH}) ; \sim 1745(\mathrm{OAc}), 1460,1430, \sim 1375(\mathrm{OAc}), 1250,1230,1175$, $1135,1095,1045,1030,985,975,940,900,845 \mathrm{~cm}^{-1}$.

NMR spectrum (benzene- $\left.d_{6}, 100 \mathrm{MHz}\right): \delta 0.69\left(3 \mathrm{H}, \mathrm{d}, \mathrm{CH}_{3}-5\right), 1.15 \sim 1.60\left(5 \mathrm{H}, \mathrm{m} ; \mathrm{CH}_{2}-4\right.$, 
$\mathrm{CH}_{2}-6$ and $\left.\mathrm{H}-5\right), 1.67(6 \mathrm{H}, \mathrm{s}, \mathrm{OAc}-1$ and 3$), 1.76(3 \mathrm{H}, \mathrm{s}, \mathrm{OAc}-2), 4.78(2 \mathrm{H}, \mathrm{dq}, \mathrm{H}-1$ and 3$)$, $5.80[1 \mathrm{H}$, a triplet $(J \sim 2.5 \mathrm{~Hz})$ with a small couplings $(J \sim 0.5 \mathrm{~Hz}), \mathrm{H}-2] ; J_{1,2}$ and $J_{2,3} \sim 2.5 \mathrm{~Hz}$, $J_{1,6 \mathrm{e}}$ and $J_{3,40} 5.5 \mathrm{~Hz}, J_{1,6 \mathrm{a}}$ and $J_{3,4 \mathrm{a}} 11 \mathrm{~Hz}, J_{2,4 \mathrm{e}}$ and $J_{2,6 \mathrm{e}} \sim 0.5 \mathrm{~Hz}$ (a long-range coupling in the W-configuration). On irradiation at $\delta 5.80(\mathrm{H}-2)$, a double quartet at $\delta 4.78(\mathrm{H}-1$ and 3) changed into a quartet $(J 5.5$ and $11 \mathrm{~Hz})$. On irradiation at $\delta 1.42\left(\mathrm{CH}_{2}-4, \mathrm{CH}_{2}-6, \mathrm{H}-5\right)$, a double quartet of $\mathrm{H}-1$ and $\mathrm{H}-3$ change into a doublet $(\mathrm{J} \sim 2.5 \mathrm{~Hz})$. On simultaneous irradiation at $\delta 1.43$ and $5.80(\mathrm{H}-2)$, a double quartet of $\mathrm{H}-1$ and $\mathrm{H}-3$ collapsed to a singlet. On irradiation at $\delta 4.78(\mathrm{H}-1$ and 3$)$, unresolved triplet of $\mathrm{H}-2$ collapsed to a singlet-like signal with a small couplings $(J \sim 0.5 \mathrm{~Hz})$.

Treatment of KD16-U1 with methanol and sulfuric acid (formation of 7).

To a suspension of KD16-U1 (300 mg) in methanol $(15 \mathrm{ml})$, a few drops of conc. sulfuric acid were added and the resulting solution was heated in sealed tube at $100^{\circ} \mathrm{C}$ for 40 minutes. Silica gel TLC with ethyl acetate-methanol $(6: 1)$ showed that the starting material (Rf 0.46 ) was replaced by a new spot $(8, \mathrm{Rf} 0.60)$. The reaction mixture was neutralized to $\mathrm{pH} 7$ with $1 \mathrm{~N}$ aqueous ammonia and evaporated. The residue was chromatographed on a column of silica gel with the same solvent system to give 7. Recrystallization from ethyl acetate-ethanol gave colorless plates of 7; yield $216 \mathrm{mg}(67 \%)$; mp $151 \sim 153^{\circ} \mathrm{C}$; $[\alpha]_{\mathrm{D}}^{22}-150^{\circ}$ (c 1.0, methanol).

Found: C 50.74, $\mathrm{H}$ 6.36. Calcd. for $\mathrm{C}_{8} \mathrm{H}_{12} \mathrm{O}_{5}$ : C $51.06, \mathrm{H} 6.43 \%$.

Mass spectrum $(\mathrm{m} / \mathrm{e})$ : 188 (molecular ion), 170, 156, 141, 138, 128, 110, 109, 96.

IR spectrum $(\mathrm{KBr}): 3450 \sim 3350(\mathrm{OH}), 2930,2850(\mathrm{CH}), \sim 1675(\mathrm{C}=\mathrm{O}), 1650 \sim 1620 \mathrm{~cm}^{-1}$ $(\mathrm{C}=\mathrm{C})$.

UV spectrum: $\lambda_{\max }^{\mathrm{H}_{20}} 226(\varepsilon 7,000) ; \lambda_{\mathrm{max}}^{0.1 \mathrm{NHCl}} 226(\varepsilon 7,100) ; \lambda_{\max }^{0.1 \mathrm{NaOH}} 218(\varepsilon 3,200), 267(\varepsilon$ $5,900)$ and $300 \mathrm{~nm}$ (sh., $\varepsilon 3,200)$.

NMR spectrum $\left(\mathrm{D}_{2} \mathrm{O}, 60 \mathrm{MHz}\right): \delta 3.32\left(3 \mathrm{H}, \mathrm{s}, \mathrm{OCH}_{3}\right), 4.13\left(2 \mathrm{H}, \mathrm{m}, \mathrm{CH}_{2}-6\right), \sim 4.45(2 \mathrm{H}$, $\mathrm{m}, \mathrm{H}-5$ and $\mathrm{H}-6), 4.82(1 \mathrm{H}, \mathrm{m}, \mathrm{H}-4), 6.84(1 \mathrm{H}, \mathrm{m}, \mathrm{H}-3)$.

Formation of 8 from 7 . A solution of $7(50 \mathrm{mg})$ in methanol $(2 \mathrm{ml})$ was treated with palladium black and hydrogen in the similar way to the hydrogenation of $\mathbf{3}$. The resulting syrup $(50 \mathrm{mg})$ was treated with acetic anhydride and perchloric acid as described in the acidic acetylation of KD16-U1. The crude syrup was chromatographed on a short column of silica gel with ethyl acetate - methanol $(6: 1)$ to give a thick syrup, $67 \mathrm{mg}(81 \%) ;[\alpha]_{D}^{18}+56^{\circ}(c 2.3$, chloroform).

Found: C 52.81, H 6.42. Calcd. for $\mathrm{C}_{14} \mathrm{H}_{20} \mathrm{O}_{8}$ : C 53.17, $\mathrm{H} 6.64 \%$.

IR spectrum: $\sim 2900(\mathrm{CH}), 1765 \sim 1740(\mathrm{OAc}), 1710(\mathrm{C}=\mathrm{O}), 1375(\mathrm{OAc}), 1250 \sim 1210 \mathrm{~cm}^{-1}$.

NMR spectrum $\left(\mathrm{CDCl}_{3}, 100 \mathrm{MHz}\right): \delta 2.02,2.10$ ard 2.13 (each $3 \mathrm{H}$, s, OAc), $1.8 \sim 2.5$ $(2 \mathrm{H}, \mathrm{m}, \mathrm{H}-5 \mathrm{a}$ and $5 \mathrm{e}), 2.6 \sim 2.95(1 \mathrm{H}, \mathrm{m}, \mathrm{H}-6), 3.34\left(3 \mathrm{H}, \mathrm{s}, \mathrm{OCH}_{3}\right), 3.46$ and 3.75 (each $1 \mathrm{H} \mathrm{q}$, an $\mathrm{AB}$ part of $\mathrm{ABX}$ system), 5.38 (d, H-2), 5.40 (dq, H-4), 5.80 (m, H-3). By double resonance technique, following coupling constants were confirmed: $J_{2,3} 3.5 \mathrm{~Hz}, J_{3,4} \sim 2 \mathrm{~Hz}$, $J_{4,5 e} 5 \mathrm{~Hz}, J_{4,5 \mathrm{a}} \sim 13 \mathrm{~Hz}, J_{5 \mathrm{e}, \mathrm{e}} \sim 5 \mathrm{~Hz}, J_{5 \mathrm{a}, 8} \sim 13 \mathrm{~Hz}, J_{6,7} 7 \mathrm{~Hz}, J_{6,7^{\prime}} 5 \mathrm{~Hz}, J_{7,7^{\prime}} 10 \mathrm{~Hz}, J_{2,8}<1 \mathrm{~Hz}$, $J_{3,5 \mathrm{e}} \sim 2 \mathrm{~Hz}$.

Acknowledgement

We wish to thank Mr. SABURo NAKADA of our laboratory for carrying out elementary analysis.

\section{References}

1) Umezawa, S.; Tsuchiya, K. Tatsuta, Y. Horiuchi, T. Usui, H. Umezawa, M. Hamada \& A. YAGI: A new antibiotic, dienomycin. I. Screening method, isolation and chemical studies. J. Antibiotics 23: 20 27, 1970

2) Umezawa, S.; K. Tatsuta, K. Fujimoto, T. Tsuchiya, H. Umezawa \& h. Naganawa: Structure of antipain, a new SAKAGUCHI-positive product of Streptomyces. J. Antibiotics 25: 267 $\sim 270,1972$

3) Tatsuta, K.; T. Tsuchiya, S. Umezawa, H. Naganawa \& H. Umezawa: Revised structure for arglecin. J. Antibiotics 25: 674 676, 1972 
4) Umezawa, S.; K. Tatsuta, O. Izawa, T. Tsuchiya \& H. Umezawa: A new microbial metabolite phosphoramidon. Tetrahedron Letters 1972: 97 100, 1972

5) Freeman, G.C.; J.E. Gill \& W.S. WAring: The structure of trichothecin and its hydrolysis products. J. Chem. Soc. 1959: 1105 1132, 1959

6) Closse, A.; R. Mauli \& H. P. Sigg: Die Konstitution von Epoxidon. Helv. Chim. Acta 49: 204 213, 1966

7) Fatiadi, A.J. \& H.S. Isbell: Cyclic polyhydroxy ketones. II. xylo-Trihydroxycyclohexenediolic acid and keto-inositols. J. Research National Bureau Standards A 68A: 287 299, 1964

8) Baltzly, R. \& J.S. Buck: Catalytic Debenzylation. The effect of substitution on strength of the $O$-benzyl and N-benzyl linkages. J. Amer. Chem. Soc. 65: 1984 1992, 1943

9) Jackman, L. M. \& S. Sternhell: Application of nuclear magnetic resonace spectroscopy in organic chemistry. p. 338, Pergamon Press, Oxford, 1969

10) Hall, L. D.: The conformations of cyclic compound in solution. I. Shikimic acid. J. Org. Chem. 29: 297 299, 1964

11) Miller, M.W.: The structure of terremutin. Tetrahedron 24: 4839 4851, 1968 